by 30 -s reocclusion) within 1 min of reperfusion, and the delayed postconditioning group were given the procedure more than $1 \mathrm{~min}$ after the onset of reperfusion.

Results There were no significant difference between the three groups in age, sex, plasma lipid, smoking rate, morbidity of hypertension and diabetes mellitus. The baseline arterial diameter and FMD before IR had no difference between the three groups (IR:3.84 \pm 0.66 , postconditioning: $3.76 \pm 0.68$, delayed postconditioning: $3.80 \pm 0.72, p<0.05$ ). Flow-mediated dilation was reduced by IR in the three groups (IR: $8.37 \pm 2.76$ vs $3.05 \pm 0.91, p<0.05$; Postconditioning: $8.22 \pm 2.48$ vs 6.70 $\pm 2.36, \mathrm{p}<0.05$; Delayed postconditioning: $8.52 \pm 2.35$ vs $3.17 \pm 1.04$, $\mathrm{p}<0.05)$. FMD of Postconditioning group was much higher than that of the IR group $(6.70 \pm 2.36$ vs $3.05 \pm 0.91, p<0.05)$, while no protection was observed when the application of postconditioning was delayed for $1 \mathrm{~min}$ after the onset of reperfusion (3.17 \pm 1.04 vs 3.05 $\pm 0.91, \mathrm{p}>0.05$ ).

Conclusions Endothelial function was damaged by IR. Postconditioning applied within 1 min of reperfusion might protect against endothelial IR injury, while the protective effect disappeared when the postconditioning applied more than $1 \mathrm{~min}$ after the onset of reperfusion.

\section{GW23-e0458 EFFECT OF POSTCONDITIONING AND DELAYED POSTCONDITIONING ON ENDOTHELIAL FUNCTION IN ELDERLY PATIENTS WITH CORONARY DISEASE DURING ISCHAEMIA-REPERFUSION}

doi:10.1136/heartjnl-2012-302920j.44

${ }^{1}$ Ma Xiao-jing, ${ }^{1}$ Zhang Xing-hua, ${ }^{2}$ Ma Hong-jun, ${ }^{1}$ Ma Xiao-jing. ${ }^{1}$ Provincial Hospital Affiliated to Shandong University; ${ }^{2}$ Shandong Provincial Academy of Medical Science

Objectives Although successful restoration of blood flow is mandatory of salvage of ischaemic tissue, reperfusion can paradoxically place tissue of further injury. The aim of this study was to observe the effect of postconditioning and delayed postconditioning on endothelial function in elderly patients with coronary disease during forearm ischaemia reperfusion (IR).

Methods Fifty-four elderly patients (average age: $66.44 \pm 5.49$ years) with coronary disease were recruited in this study, and randomised to three groups, IR group, postconditioning group and delayed postconditioning group. Brachial artery endothelial function was assessed by ultrasound to measure flow-mediated dilation (FMD). FMD was measured before and after IR (20 min of arm ischaemia followed by $20 \mathrm{~min}$ of reperfusion). Postconditioning group were given postconditioning (three cycles of 30 -s reperfusion followed 